Blaise Cronin and Cassidy R. Sugimoto., eds. Scholarly Metrics Under the Microscope: From Citation Analysis to Academic Auditing. Series: ASIST Monograph. Medford: Information Today. 2015. 976 pp. ISBN-13: 978-1573874991

"What began life as a tool for retrieving the literature of science, ..., has become, unwittingly, the basis of a system for calibrating scientific performance and shaping careers," (Cronin and Sugimoto).

This quote will resonate with many academics/researchers. Given the current emphasis on performance and reputation building, as demonstrated by academics' on-going quest to increase citation rates and $h$-index, it is easy to lose sight of the original intent of citation indexes; even more so when one discovers that some administrators in academe see a relationship between salaries and citation rates (Jonker and Hicks).

This book consists of a representative cross-section of writings published on scholarly metrics between 1955 and 2014 and is meant to serve as a one-stop resource that focuses on the theoretical, conceptual, methodological, and ethical concerns associated with scholarly metrics. It is also a comprehensive and critical reader of the birth and development of scholarly metrics as reflected in the literature. The papers (55 of them) are essentially reprints of the originals as only minimal changes (such as the removal of fax numbers, e-mail addresses and such) were made.

The documents are not arranged in chronological order, but the first one takes the reader back to the 1955 paper by Eugene Garfield: "Citation Indexes for Science: A New Dimension in Documentation Through Association of Ideas", originally published in Science. Reading this paper reminds one that the original intent was to create a tool for literature research, to provide researchers with the ability to trace the origin of ideas and to "eliminate the uncritical citation of fraudulent, incomplete or obsolete data by making it possible for the conscientious scholar to be aware of criticisms of earlier papers." (Cronin and Sugimoto).

In working through this volume, the variety of readings is refreshing. The editors collected scholarly papers, editorial commentaries, blog posts, and letters that elucidate current trends and explain the history of how we arrived at the various applications of scholarly metrics.

This mammoth work, comprising almost 1000 pages, is arranged according to six different themes: 1) Concepts and theories, 2) Validity issues, 3) Data sources, 4) Indicators, 5) Science policy, and 6) Systemic effects. Each section consists of between seven and eleven contributions. As the editors indicate in the introduction, one could possibly argue for a different arrangement of these papers according to different criteria, but these themes appear to work well enough to produce a framework that is conducive to exploring the breadth and depth of scholarly metrics and its many variants. 
The editors start each of the six sections with a "scene-setting" introduction which is helpful in providing additional context for the papers collected in that specific section. It is also beneficial to have the goals of the section presented to the reader in these introductions.

In the first section, "Concepts and Theories", some attention is given to the problems arising from the way in which citations are used. It is pointed out that references to other papers are done for various reasons, and that counting and comparing the numbers of citations would be a valid exercise only if these references were normatively governed and consistently applied. However, since such behaviour is inherently subjective, depending on circumstance and authors' motivation, the use thereof for faculty evaluations is highly questionable at best. Some attention is also given to more recent developments, such as webometrics and altmetrics, pointing out that there are many questions that remain unanswered in the use of these metrics.

"Validity Issues" is the theme of part two. The susceptibility of citation analysis to manipulation, and the practice by some authors to select citations to serve their scientific, political and personal goals are examples of some of the problems tackled in this section. Self-citation; collegiate citation; and the phenomenon that unfounded but much cited claims are sometimes accepted as fact because they are often cited, are also discussed. Furthermore it is pointed out that both the $h$-index and the Journal Impact Factor (JIF) are measures of utility rather than quality; something that we tend to forget in our fervor to achieve quantifiable measures of quality.

Part three is devoted to the theme of "Data Sources". In this section issues such as underrepresentation of journals from the Third World, English-language bias, incomplete journal coverage, and weak monograph coverage are discussed. The problems in using data derived from Google's book search and even the use of Google Scholar for obtaining Journal Impact Factors are also addressed. Usage data collected at the article level, as found in services such as Mendeley, CiteULike and open peer review systems (e.g. Peer Evaluation and PaperCritic), are also put under the spotlight.

The fourth theme addressed in the book is that of "Indicators". Indicators such as the Journal Impact Factor and $h$-index derive their popularity, at least in part, from their simplicity. For example, if a journal has a JIF of 8.7 or a researcher an $h$-index of 14 , these numbers immediately convey the reputation and standing of the journal relative to other academic journals and that of the researcher relative to his or her peers. With regards to the $h$-index, it is worthwhile to read the Jorge Hirsch' original: "An Index to Quantify an Individual's Scientific Research Output" paper in which this index was first proposed. Since Hirsch suggested that the $h$-index might provide a means of comparing different individuals objectively, quite a number of his peers took the trouble to point out the shortcomings of this index. Problems with the statistical reliability and inconsistency inherent to the index are discussed in other papers in this section. The Crown Indicator, which is a measure of the combined output of a research group, is also scrutinized and the shortcomings thereof are pointed out.

"Science Policy" is the broad theme of part five. This section focuses on the use of bibliometric/scientometric indicators as a means to evaluate research output. The 
incompatibility and significant distortions in research evaluation because of the difference between the research done in the public and private sectors and the differences in scientific specialization found in different universities around the world, receive some attention. It is also pointed out that these differences are exacerbated by the fact that disciplines display different publication behavior (some disciplines favour monographs and others favor journal articles). For example Web of Science and Scopus are often used in research evaluation exercises; therefore, journal articles have an advantage, since that is what Web of Science and Scopus offer. Moreover, the risks and social consequences of using bibliometric measures for research evaluation, in terms of quality and quantity, are discussed. An interesting article: "Looks Good on Paper: A Flawed System for Judging Research Is Leading to Academic Fraud" published in 2013 in The Economist provides some worthwhile reading on the "industry of plagiarism, invented research and fake journals" (Cronin and Sugimoto) which the author claims resulted from the practice of research administrators placing rewards and promotion on the number of publications produced.

The final section of this book is titled "Systemic Effects". This section explores how the reliance on metrics changes the values, motivation and behaviors of researchers and academics. The various metrics allow researchers to define the output and measure the impact of their research, which enhances their reputation and betters their chances of obtaining funds for even more research. There are also a couple of papers bemoaning the mindless pursuit of citation counting and the impact of bibliometrics on the allocation of resources, which ultimately forces researchers and academics to conform to the general practice of cultivating a higher $h$-index.

\section{Scholarly Metrics Under the Microscope: from Citation Analysis to Academic} Auditing will be a valuable addition to any academic library. The editors (Cronin and Sugimoto) are well-known authors and specialists in the field of bibliometrics/scientometrics, and Blaise Cronin received the 2013 Derek Price Medal Prize for his distinguished contributions to the field of scientometrics (Sugimoto).

The editors did an excellent job collecting stimulating and relevant papers. This book would be of interest to anyone involved in scholarly research and publishing. Academics, faculty, administrators, scholars, publishers, information scientists and research policymakers will find it a worthwhile read.

Marinus Swanepoel, Professional Librarian, marinus.swanepoel@uleth.ca, University of Lethbridge, Lethbridge, AB.

\section{Works Cited}

Cronin, Blaise, and Cassidy R. Sugimoto. Scholarly Metrics Under the Microscope: From Citation Analysis to Academic Auditing. Medford: Association for Information Science and Technology, 2015. Print. 
Partnership: the Canadian Journal of Library and Information Practice and Research, vol. 10, no. 1 (2015)

Jonker, Linda, and Martin Hicks. "Teaching Loads and Research Outputs of Ontario University Faculty Members: Implications for Productivity and Differentiation." Higher Education Quality Council of Ontario (HEQCO). Mar. 2014. Web.

Sugimoto, Cassidy R. "Blaise Cronin Wins the 2013 Derek John de Solla Price Medal." Scientometrics 98.1 (2014): 5-10. 